\title{
Differential effects of sulforaphane on histone deacetylases, cell cycle arrest and apoptosis in normal prostate cells versus hyperplastic and cancerous prostate cells
}

\author{
John D. Clarke ${ }^{1,2}$, Anna Hsu², Zhen Yu², Roderick H. Dashwood ${ }^{3,4}$, and Emily Ho ${ }^{2,3,{ }^{*}}$ \\ ${ }^{1}$ Molecular and Cellular Biology Program, Oregon State University, Corvallis, OR 97331 \\ 2Department of Nutrition and Exercise Sciences, Oregon State University, Corvallis, OR 97331 \\ ${ }^{3}$ Linus Pauling Institute, Oregon State University, Corvallis, OR 97331 \\ ${ }^{4}$ Department of Environmental and Molecular Toxicology, Oregon State University, Corvallis, OR \\ 97331
}

\section{Abstract}

Sulforaphane (SFN) is an isothiocyanate derived from cruciferous vegetables such as broccoli. The ability of SFN to inhibit histone deacetylase enzymes may be one mechanism by which it acts as a chemoprevention agent. The ability of a chemopreventive agent to specifically cause cytotoxicity in cancer, not normal cells is an important factor in determining its safety and clinical relevance. We characterized the effects of SFN in normal (PrEC), benign hyperplasia (BPH1) and cancerous (LnCap and PC3) prostate epithelial cells. We observed that $15 \mu \mathrm{M}$ SFN selectively induced cell cycle arrest and apoptosis in BPH1, LnCap and PC3 cells but not PrEC cells. SFN treatment also selectively decreased HDAC activity, and Class I and II HDAC proteins, increased acetylated histone $\mathrm{H} 3$ at the promoter for $P 21$, induced 21 expression and increased tubulin acetylation in prostate cancer cells. HDAC6 over-expression was able to reverse SFN-induced cyotoxicity. In PrEC cells, SFN caused only a transient reduction in HDAC activity with no change in any other endpoints tested. The differences in sensitivity to SFN in PrEC and PC3 are likely not due to differences in SFN metabolism or differences in phase 2 enzyme induction. From these data we conclude that SFN exerts differential effects on cell proliferation, HDAC activity and downstream targets in normal and cancer cells.

\section{Keywords}

apoptosis; chemoprevention; epigenetics; isothiocyanate; prostate cancer

\section{Introduction}

Epidemiologic studies suggest that cruciferous vegetable intake may lower the overall risk of prostate cancer [1, 2]. Sulforaphane (SFN) is an isothiocyanate derived from cruciferous vegetables such as broccoli and broccoli sprouts [3]. The majority of chemoprevention studies have focused on the ability of SFN to act "pre-initiation" as a potent phase 2 enzyme inducer via Keap1-Nrf2 signaling and antioxidant response element (ARE)-driven gene

\footnotetext{
*Corresponding Author 117 Milam Hall, Oregon State University, Corvallis, OR 97331, Tel: 541-737-9559 Fax: 541-737-6914; emily.ho@oregonstate.edu.

Conflict of Interest

The authors have declared no conflict of interest
} 
expression. Additional evidence also suggests that SFN suppresses tumor development during the "post-initiation" phase of cancer via induction of cell cycle arrest and apoptosis $[4,5]$. Recently, a novel suppression mechanism involving the ability of SFN to inhibit histone deacetylase (HDAC) enzymes, alter histone acetylation and affect gene regulation has been reported [6-8].

Lysine acetylation and deacetylation is a dynamic process executed by histone acetyltransferases (HAT) and HDACs that can affect intermolecular interactions and/or the stability and activity of proteins. Currently there are 11 trichostatin A (TSA) sensitive HDACs which are divided into four classes (class I, IIa, IIb, and IV) according to structure, expression patterns, and subcellular localization. The class I HDACs consists of HDACs 1, 2,3 , and 8 and are expressed in all tissues. They are predominantly found in the nucleus and are mainly responsible for histone deacetylation. HDACs 4, 5, 7, and 9 belong to class IIa and have a more restricted expression pattern, being found predominantly in tissues such as muscle, brain, heart, endothelial cells, and thymocytes [9]. The class IIb HDACs consists of HDAC 6 and 10, with HDAC6 being primarily localized in the cytoplasm and targeting nonhistone substrates, while little is currently known about HDAC10.

In general, addition of acetyl groups to histones by HATs promotes gene expression by creating an "open" chromatin conformation and acts as a docking site for bromo domain containing transcription machinery, thereby facilitating access to DNA and organization of transcription. Removal of acetyl groups by HDACs results in a "closed" conformation and expulsion of transcription activating components, ultimately repressing transcription. In addition to histone proteins, the acetylation of lysine residues on non-histone proteins by Class II HDACs plays a major role in many different cellular processes [10]. A well studied example is HDAC6 which has multiple non-histone substrates including $\alpha$-tubulin and HSP90 [11]. The functional consequences of the acetylation and deacetylation of $\alpha$-tubulin are alterations in microtubule dynamics and stability, cell migration, aggresome formation, and autophagy $[12,13]$. All of these processes are critically important in regulating cell cycle arrest, misfolded protein toxicity, and cell death. Currently little is known regarding the effects of dietary HDAC inhibitors on non-histone protein acetylation, and changes in Class I and Class II HDACs.

Pharmacological HDAC inhibitors, including suberoylanilide hydroxamic acid (SAHA), valproic acid, depsipeptide, and phenyl butyrate have been shown to be effective agents against prostate cancer in cancer cell lines and in xenograft models [14, 15]. Similar to pharmacological HDAC inhibitors, SFN inhibits HDAC activity and suppresses prostate tumor growth both in vitro and in vivo [7, 8]. Furthermore, HDAC inhibitors such as SAHA, TSA, and other novel hydroxamic acids are selectively growth inhibitory and cytotoxic to cancer cells rather than normal cells [16-21]. For example, SAHA (Vorinostat) treatment in prostate cancer cells inhibited cell growth (LnCap, DU-145, and PC3) and induced cell death (LnCap and DU-145), whereas normal prostate cells (PrEC) were resistant to SAHA induced growth arrest and cell death [17]. Thus, the goal of this study was to examine the cytotoxicity of SFN in normal and cancerous prostate epithelial cell lines by characterizing the effect of SFN on cell cycle arrest, apoptosis, HDAC activity, Class I and II HDAC expression, and histone/non-histone protein acetylation.

\section{Materials and methods}

\subsection{Cell Culture}

Normal (PrEC) prostate epithelial cells were obtained from Lonza (Basel, Switzerland). Benign hyperplasia epithelial cells (BPH1) were a kind gift from Dr. Simon Hayward (Vanderbilt University Medical Center, Nashville, TN). Androgen dependent prostate cancer 
epithelial cells (LnCap) and androgen-independent prostate cancer epithelial cells (PC3) were obtained from American Type Tissue Collection (Manassas, VA). Cells were cultured at $5 \% \mathrm{CO}_{2}$ and $37^{\circ} \mathrm{C}$. PrEC cells were cultured in PrEC basal media (PrEBM) with PrEC growth media (PrEGM) SingleQuots (Lonza) and BPH1, LnCap and PC3 cells in Roswell Park Memorial Institute (RPMI) 1640 supplemented with glutamine plus 10\% fetal bovine serum (FBS) (Cellgro, Manassas, VA). The cells were treated with dimethylsufoxide (DMSO) (vehicle control) or $15 \mu \mathrm{M}$ SFN (LKT laboratories, St. Paul, MN) for the time indicated and harvested for subsequent assays. This concentration of SFN was based on previous reports showing HDAC inhibition in prostate and colon cancer cells [6, 7]. For HDAC6 over-expression $2.0 \times 10^{4}$ cells per well were seeded in 96-well plates. For each well $20 \mu \mathrm{L}$ of Opti-MEM reduced serum media (Invitrogen) was mixed with 50ng of either empty vector (pcDNA 3.1, Invitrogen, Carlsbad, CA) or HDAC6 plasmid (cat \# SC111132 Origene, Rockville, MD) and $0.1 \mu \mathrm{L}$ of PLUS ${ }^{\mathrm{TM}}$ reagent, and incubated for $10 \mathrm{~min}$ at room temperature. Lipofectamine $\mathrm{LTX}^{\mathrm{TM}}(0.3 \mu \mathrm{L})$ was added and the solution was incubated for 30 minutes at room temperature. The DNA mix $(20 \mu \mathrm{L})$ was added to each well and cultured for 18-24 hrs. Cells were treated with DMSO or SFN as outlined above for 24 and $48 \mathrm{hr}$. Transfection efficiency was $\sim 50-65 \%$ using a GFP plasmid and measured by flow cytometry (Guava PCA). For protein over-expression the transfection procedure was scaled up to 12 well format and western blots were performed as described below.

\subsection{Western Blot Analysis}

Proteins $(10-20 \mu \mathrm{g})$ were separated by SDS-PAGE on a 4-12\% bis-Tris gel (Novex, San Diego, CA) and transferred to nitrocellulose membrane (Invitrogen). Primary antibodies from Santa Cruz Biotechnologies, Santa Cruz, CA were as follows: HDAC2 (H-54) 1:200; HDAC3 1:200; HDAC4 1:200; HDAC6 1:200; HDAC8 1:200. Other primary antibodies were: HDAC1, $1 \mu \mathrm{g} / \mathrm{mL}$ (Upstate, Billerica, MA); p21, 1:1000 (Cell Signaling, Danvers, MA); acetylated $\alpha$-tubulin 1:5000 (Sigma, St. Louis, MO); poly (ADP-ribose) polymerase (PARP) (N-20) 1:2000 (BD); $\alpha$-tubulin (Sigma); and $\beta$-actin, 1:5000 (Sigma). Detection was performed by using Supersignal West Femto Reagent (Thermo Scientific, Waltham MA) with image analysis on an AlphaInnotech photodocumentation system. Image quantification was determined by NIH ImageJ. Treatments were performed in triplicate.

\subsection{Apoptosis/Cell Viability Assays}

Cell viability was determined using the trypan blue exclusion assay. Multicaspase assay was used as a marker of apoptosis using a flow-cytometry based assay kit (Guava Technologies, Hayward, CA). Briefly, $5 \times 10^{4}$ cells were stained in triplicate with a fluorochromeconjugated caspase inhibitor, sulforhodamine-valyl-alanyl-aspartyl-fluoromethylketone (SRVAD-FMK) and 7-amino-actinomycin D (7-AAD) according to the manufacturer's instructions and analyzed on a Guava Personal Cell Analyzer (Guava PCA) (Guava Technologies).

\subsection{Cell Cycle Analysis}

A flow cytometric assay was performed to assess effects of SFN on cell cycle. One million cells were fixed in $70 \%$ ethanol. After fixation, cells were washed, pelleted, and resuspended in $0.04 \mathrm{mg} / \mathrm{ml}$ propidium iodide and $100 \mathrm{mg} / \mathrm{ml}$ RNase in PBS and analyzed on the Guava PCA. Multi-Cycle analysis software (Phoenix Flow Systems, San Diego, CA) was used to generate histograms and determine the number of cells in each phase of the cell cycle. Cells were treated in triplicate. 


\subsection{Quantitative Real-Time PCR}

Total RNA was extracted using a RNeasy kit (Qiagen, Valencia, CA). Two micrograms of RNA were reverse-transcribed using the Invitrogen Super-Script ${ }^{\circledR}$ III reverse transcriptase (Invitrogen, Carlsbad, CA) according to the manufacture's instruction. About 50ng cDNA was amplified using DyNAmo ${ }^{\mathrm{TM}}$ SYBR ${ }^{\circledR}$ Green $\mathrm{qPCR}$ Kit (New England Biolabs, Ipswich, MA) in a Chromo4 Real Time PCR detections system (MJ Research, Waltham, MA) using primers for $\mathrm{p} 21^{\text {waf } 1 / \mathrm{cip} 1}$ (F:CAGACCAGCATGACAGATTTC,

R:GCGGATTAGGGCTTCCTCTT, annealing temp $=56^{\circ} \mathrm{C}$ ), GSTP1 (F:

GCCCTACACCGTGGTCTATT, R: TGCTGGTCCTTCCCATAGAG annealing temp $=5$ $8^{\circ} \mathrm{C}$ ); H O 1 (F: CTTCTTCACCTTCCCCAAC, R: GCTCTGGTCCTTGGTGTCATA, annealing temp $=58^{\circ} \mathrm{C}$ ); NQO1 (F: AAAGGACCCTTCCGGAGTAA, R:

AGGCTGCTTGGAGCAAAATA, annealing temp $=58^{\circ} \mathrm{C}$ ); $\beta$-actin $\mathrm{F}$ : CTTCCAGCCTTCCTTCCTGGGCATG, R: GCTCAGGAGGAGCAATGATCTTGATC, annealing temp $=56^{\circ} \mathrm{C}$ ) PCR conditions were as follows: $95^{\circ} \mathrm{C} / 10 \mathrm{~min} ; 40$ cycles: $94^{\circ} \mathrm{C} / 10$ sec, annealing temperature $/ 20 \mathrm{sec}$ and $72^{\circ} \mathrm{C} / 20 \mathrm{sec}$; melting curve $60-95^{\circ} \mathrm{C}$ read every 0.2 sec; $72^{\circ} \mathrm{C} / 10 \mathrm{~min}$. Cells were treated in triplicate.

\subsection{LC-MS/MS}

The methods for LC-MS/MS analysis were adapted from Al Janobi et al [22]. For cellular metabolite analysis, cells were treated in duplicate with SFN or vehicle for a time course up to $72 \mathrm{~h}$ and $\sim 5 \times 10^{5}$ cells were dedicated to MS analysis. Cell pellets were resuspended in $100 \mu \mathrm{L}$ of $0.1 \%$ formic acid in water, vortexed and frozen at $-80^{\circ} \mathrm{C}$. After being thawed the samples were vortexed again and centrifuged at $11,600 \times \mathrm{g}$ for 5 minutes at $4^{\circ} \mathrm{C}$. The supernatant was collected and acidified with $10 \mu \mathrm{L}$ of trifluoracetic acid. The samples were centrifuged as before and the supernatants were collected and filtered through a $0.2 \mu \mathrm{m}$ filter. For metabolite analyses in cell culture media, $500 \mu \mathrm{L}$ of spent media was saved and immediately acidified with precooled $\left(4^{\circ} \mathrm{C}\right)$ trifluoracetic acid $(10 \%)$. The samples were centrifuged at $11,600 \times \mathrm{g}$ for 5 minutes at $4^{\circ} \mathrm{C}$ and subsequently filtered through a $0.2 \mu \mathrm{m}$ filter.

Ten $\mu \mathrm{L}$ of sample were separated on a Shimadzu Prominence HPLC (Shimadzu, Kyoto, Japan) using a reversed-phase Phenomenex synergi $4 \mu \mathrm{m}$ hydro RP $80 \AA 250 \times 1.0 \mathrm{~mm}$ HPLC column. The flow rate was $0.1 \mathrm{~mL} / \mathrm{min}$ using $0.1 \%$ formic acid in water (solution A) and $0.1 \%$ formic acid in acetonitrile (solution B). The gradient was as follows: $5 \% \mathrm{~B}$ increasing to $30 \%$ (7 min), held at 30\% (6 min), washed out with $90 \% \mathrm{~B}(10 \mathrm{~min})$ and reequilibrated to 5\% B (5 min). The LC eluent was sprayed into an API triple quad mass spectrometer 3200 (Applied Biosystems, Foster City, CA) by electrospray ionization in positive mode. Tandem mass spectrometry using multiple reaction monitoring was used to detect the analytes with the following precursor and product ions: SFN $(178>114)$, SFNGSH (485>114), SFN-CG (356>114), SFN-Cys (299>114), SFN-NAC (341>114). Spike and recovery experiments confirmed that $>95 \%$ of all compounds were recovered following the processing protocols outlined.

\subsection{HDAC activity assays}

HDAC activity was assayed using the 386 well format Fluor-de-Lys HDAC activity kit (Upstate) as described in [6]. Five $\mu \mathrm{g}$ of total cell lysate were added to each well and assay was performed according to the manufacturer's instructions. Fluorescence was measured and recorded as arbitrary fluorescence units (AFU) using a Spectra Max Gemini XS fluorescent plate reader (Molecular Devices, Sunnyvale, CA). 


\subsection{Chromatin Immunoprecipitation}

ChIP assays were performed to examine the association of acetylated histone $\mathrm{H} 3$ with $P 21$ promoter as described previously [7]. As a positive control PC3 cells were also treated with $0.3 \mu \mathrm{M}$ Trichostatin A (Enzo Life Sciences International, Inc, Plymouth Meeting, PA) for 8 $\mathrm{h}$ and harvested for the ChIP assay. An acetylated histone H3 ChIP kit (Upstate) was used according to the manufacturer's instructions. Quantification of ChIP DNA was performed by using DyNAmo ${ }^{\mathrm{TM}} \mathrm{SYBR}{ }^{\circledR}$ Green using primers for P21 ${ }^{\text {waf1/cip } 1}$ (F: GGTGTCTAGGTGCTCCAGGT, R: GCACTCTCCAGGAGGACACA). The immunoprecipitated DNA was normalized to input DNA and expressed as percentage of

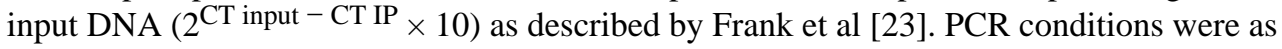
follows: $95^{\circ} \mathrm{C} / 10 \mathrm{~min} ; 40$ cycles: $94^{\circ} \mathrm{C} / 10 \mathrm{sec}, 63^{\circ} \mathrm{C} / 20 \mathrm{sec}$ and $72 \mathrm{C}^{\circ} / 20 \mathrm{sec}$; melting curve $60-95^{\circ} \mathrm{C}$ read every $0.2 \mathrm{sec} ; 72^{\circ} \mathrm{C} / 10 \mathrm{~min}$. Treatments were performed in triplicate.

\subsection{Statistical analysis}

All experiments except LC-MS/MS experiments were done in triplicate. The acetyl-histone ChIP and the HDAC6 over-expression experiments were analyzed by Student's t-test comparing the SFN treatment effect. The trypan blue exclusion time course was analyzed by two-way ANOVA. All other experiments were analyzed using one-way ANOVA with Dunnett's post-test comparing the mean SFN treatment effect for PrEC against each of the other cell lines.

\section{Results}

\subsection{SFN preferentially induced apoptosis and cell cycle arrest in BPH1, LnCap and PC3 cells}

An induction of apoptosis was observed in BPH1 and PC3 cells following $48 \mathrm{~h} \mathrm{SFN}$ treatment, as indicated by increases in multicaspase activity (Fig. 1A). LnCap cell showed a trend towards increased caspase activity at $48 \mathrm{~h}$ but it was not significantly different than the SFN effect observed in PrEC cells. No effect on cell viability in PrEC cells with a dose range of $0-15 \mu \mathrm{M}$ for $24 \mathrm{~h}$ was observed, as assessed by trypan blue exclusion assay ( $\mathrm{p}=0.63$ by one-way ANOVA). Two-way ANOVA analysis of $15 \mu \mathrm{M}$ SFN treatment in a time course up to $72 \mathrm{~h}$ in PrEC cells showed no significant treatment or interaction effect, although the time effect was significant ( $\mathrm{p}<0.0001$ ) (Fig. 1B). A striking difference between PrEC cells and the other cell lines was seen in cell cycle kinetics at 24 and $48 \mathrm{~h}$ of SFN treatment. At $24 \mathrm{~h} \mathrm{SFN}$ strongly induced a $\mathrm{G}_{2} / \mathrm{M}$ cell cycle arrest in BPH1 and PC 3 cells but had no effect on cell cycle in PrEC cells (Fig. 2). Similar to previous published data [24], SFN caused significant changes in cell cycle distribution in LnCap cells at $48 \mathrm{~h}$. Taken together these data provide evidence that SFN is preferentially cytotoxic to BPH1, LnCap and PC3 cells.

\subsection{Induction of phase 2 enzymes in all cell lines and relationship to SFN metabolism}

The canonical chemoprevention pathway for SFN involves induction of phase 2 enzymes via activation of the Nrf2 transcription factor. We tested all four prostate cell lines for the induction of several phase 2 enzymes known to be induced by SFN: glutathione-Stransferase- $\pi 1$ (GSTP1), Heme oxygenase (HO1) and NAD(P)H:quinone reductase (NQO1). No differences in the induction of HO1 and NQO1 were observed between the cell lines following $12 \mathrm{~h} \mathrm{SFN} \mathrm{treatment.} \mathrm{No} \mathrm{induction} \mathrm{of} \mathrm{GSTP1} \mathrm{was} \mathrm{observed} \mathrm{at} 12 \mathrm{~h}$ in any cell line (Fig. 3). These data indicate that SFN treatment similarly induces the phase 2 enzymes HO1 and NQO1 in normal, hyperplastic and cancerous cell lines.

To confirm equivalent dosing and assess any possible differences in metabolism that may have contributed to the differences observed in cell fate, SFN and its metabolites were 
measured in culture media and the cell lysates for all four cell lines at selected time points using LC-MS/MS. All cell lines were similar regarding the metabolism of SFN at 24 and $48 \mathrm{~h}$ (data not shown) and therefore we chose to focus on normal PrEC and late-stage androgen independent PC3 and perform a rigorous SFN time course. The overall loss of SFN and its metabolites in both the media and in the lysate was similar in PrEC and PC3 cells, with a $\sim 50 \%$ decrease detected after $24 \mathrm{~h}$ (Fig. 4A). In the cell culture media the sum of all SFN compounds was similar between the cell lines (Fig. 4A). For the individual SFN compounds a trend towards a $2-3 \mu \mathrm{M}$ shift in metabolite ratio from free SFN to the glutathione conjugate (SFN-GSH) was observed in the PrEC media at 24, 48, and $72 \mathrm{~h}$, and the cysteinyl conjugate (SFN-Cys) was detected at similar levels in the media from both cell lines (Fig. 4B). In the cell lysates, the sum of all SFN compounds was similar in both cell lines (2.8 and $2.7 \mathrm{nmol} / \mathrm{mg}$ in PrEC and PC3, respectively, at $0.5 \mathrm{hr}$ ) although a trend towards differences was observed at 2 and $5 \mathrm{~h}$ (Fig. 4A). The cellular concentration of SFNCys, one of the putative HDAC inhibitor forms of SFN, was similar in both cell lines (Fig. 4C). The other known metabolites of SFN, cysteinyl-glycine and N-acetlycysteine (SFNNAC) conjugates, were not detected in either the cell lysate or the culture media. Overall these metabolite data show that the metabolite profiles and exposure times/concentrations are similar between PrEC and PC3 cell lines.

\subsection{SFN inhibits HDAC activity in prostate cells}

At $24 \mathrm{~h}$ HDAC inhibition was observed in all cell lines and LnCap was the only line to have significantly greater HDAC inhibition compared to PrEC cells (Fig. 5). By $48 \mathrm{~h} \mathrm{SFN}$ induced HDAC inhibition was sustained in BPH1, LnCap and PC3 cells but not in PrEC, suggesting a transient inhibition of HDAC activity in normal prostate cells.

\subsection{SFN selectively decreases HDAC protein expression in BPH1, LnCap and PC3 cells}

Class I HDACs $(1,2,3,8)$ and Class II HDACs $(4,6)$ were evaluated by immunoblotting (Fig. 6). No change in Class I HDAC protein expression was apparent with SFN treatment in PrEC cells. In BPH1 cells the protein levels of HDAC2 and HDAC3 were decreased at $48 \mathrm{~h}$ after SFN treatment. In LnCap cells the only class I HDAC to decrease was HDAC3 at $48 \mathrm{~h}$ after SFN treatment. In PC3 cells the protein levels of HDAC3 was decreased at $48 \mathrm{~h}$ after SFN treatment (Fig. 6A). Among the Class II HDACs, HDAC4 protein expression decreased in all cell lines at one or both time points depending on the cell line. The other class II HDAC tested, HDAC6, showed the most robust and consistent decrease in protein level in BPH1, LnCap and PC3 cells at both 24 and $48 \mathrm{~h}$ after SFN treatment. This decrease in HDAC6 was not observed in PrEC cells (Fig. 6B). To assess the possibility that changes in HDAC6 protein expression contribute to the SFN mediated cell death, HDAC6 was overexpressed in PC3 cells followed by SFN treatment. Over-expression of HDAC6 protected PC3 cells from the SFN-induced decrease in cell viability (Fig. 7).

\subsection{SFN increases acetylated histone association on the P21 promoter and increases acetylation of cytosolic protein targets in BPH1, LnCap and PC3 cells}

P21 is commonly upregulated by HDAC inhibitors via increased acetylated histones associating with its promoter [25-27]. We observed an increase in acetylated histone $\mathrm{H} 3$ at the $P 21$ promoter in PC3 cells (Fig. 8A) at a level comparable to the positive control treatment (TSA) (data not shown). No increase in acetylation at the $P 21$ promoter was observed in PrEC cells after SFN treatment. An increase in histone acetylation at the P21 promoter after SFN treatment in BPH1 cells has previously been reported [7]. Concomitant with the increased association of acetylated histones to the $P 21$ promoter, SFN treatment preferentially increased $P 21 \mathrm{mRNA}$ (data not shown) and protein levels in BPH1, LnCap and PC 3 but not PrEC cells (Fig. 8B). The induction of p21 protein was so strong in LnCap 
cells that induction in BPH1 and PC3 did not reach significance in Dunnett's post-test but clearly demonstrated a trend for increased p 21 in those cell lines.

Recent attention has focused on the non-histone deacetylation targets of HDACs. One example is $\alpha$-tubulin acetylation which is regulated by HDAC6 and is linked to downstream apoptotic mechanisms [28, 29]. An increase in acetylated $\alpha$-tubulin was detected with SFN treatment in BPH1, LnCap and PC3 cells but not in PrEC cells (Fig. 8C). These results indicate that $\mathrm{SFN}$ can increase both histone $\mathrm{H} 3$ acetylation and $\alpha$-tubulin acetylation in BPH1, LnCap and PC3 cells while having no effect in normal PrEC prostate cells.

\section{Discussion}

It is well documented that SFN can target cancer cells through multiple chemopreventive mechanisms but here we show for the first time that SFN selectively targets benign hyperplasia cells and cancerous prostate cells while leaving the normal prostate cells unaffected. Importantly, SFN selectively induced cell cycle arrest and apoptosis, specifically in hyperplastic and cancer cells. These findings regarding the relative safety of SFN to normal tissues has significant clinical relevance as the use of SFN moves towards use in human clinical trials. In addition, a reduction in HDAC activity and down-regulation of select class I and class II HDAC proteins followed by an increase in acetylation of histone $\mathrm{H} 3$ at the $P 21$ promoter and increased acetylation of $\alpha$-tubulin occurred specifically in the hyperplastic and cancer cells, not normal cells. Together these results highlight the use of dietary SFN as a safe and relatively non-toxic chemopreventive agent that could be readily achieved by simple and affordable incorporation of SFN rich foods in the diet.

The level of HDAC activity within a cell can be altered via direct inhibition of the HDAC enzyme and changes in HDAC protein levels. Previous reports indicate that SFN and its metabolites SFN-Cys and SFN-NAC can directly inhibit HDACs $[6,7,30]$, and in this report we show that SFN can also decrease protein levels of several different HDACs. We also observed that the HDAC inhibition in PrEC cells is more transient than in the other prostate cancer cell lines. The overall metabolite profiles for PrEC and PC3 cells were similar, particularly in the levels of SFN-Cys, the putative active HDAC inhibitor. Although small changes were observed between metabolite ratios in culture media and final metabolite concentrations in cell lysates, it is unlikely that a $2-3 \mu \mathrm{M}$ difference would exert a significant biological effect that would account for the marked increase in apoptosis and cell cycle arrest in PC 3 cells. In contrast, a significant reduction in HDAC protein level was observed in BPH1, LnCap and PC3 cells which produced a greater and more persistent reduction in HDAC activity. It is possible that the differential responses in HDAC activity, HDAC protein levels and ultimately downstream acetylation of histone and non-histone targets may contribute to the differential cell fate responses observed after SFN treatment.

Over-expression of Class I HDACs has been reported in prostate cancer tumors [31, 32]. Moreover, the effects of the inhibition of Class I HDACs on cycle arrest and apoptosis has been shown previously $[32,33]$. Colon cancer cells treated with $3,3^{\prime}$-Diindolylmethane (DIM), an indole found in cruciferous vegetables, induced proteasome mediated degradation of HDACs 3 and 8, acetylation of histone $\mathrm{H} 3$ at the $P 21$ promoter and ultimately induced a $\mathrm{G}_{2} / \mathrm{M}$ cell cycle arrest and apoptosis [33]. Another report showed that siRNA knockdown of HDAC3 in SW480 colon cancer cells increased acetylated H4-K12 at the $P 21$ promoter, induced p21 expression and potentiated butyrate induced cell cycle arrest and growth inhibition [34]. These reports are consistent with what we observed in our experiments, namely SFN treatment caused a decrease in several class I HDAC proteins, induction of histone acetylation at the $P 21$ promoter and ultimately induction of $\mathrm{G}_{2} / \mathrm{M}$ cell cycle arrest 
and apoptosis. This provides compelling evidence that the changes in class I HDAC proteins and histone acetylation may be responsible the changes in cell fate.

Herein we also provide evidence that HDAC6 is potentially responsible for the selective effects of SFN in cancer cells. Tubulin is a well known deacetylation target for HDAC6 and this process has an impact on microtubule dynamics $[11,13]$. Importantly, tubulin deacetylation increases the turnover rate of microtubules, and over-expression of HDAC6 augments this process [12]. Decreases in HDAC6 activity [30] and increases in tubulin acetylation [42] after SFN treatment has previously been reported by others [35]. In Gibbs et. al., researchers found that HDAC6 over-expression in LnCap cells abrogated the effects of SFN on HSP90 acetylation and inhibited its association with the androgen receptor (AR) providing further evidence that inhibition of HDAC6 was a specific target for sulforaphane [30]. Here we confirm the decrease in HDAC6 protein levels in LnCap after SFN treatment reported by Gibbs et. al. and report that HDAC6 protein levels decrease in BPH1 and PC3 cells after SFN treatment. Interestingly, Gibbs et. al. reported that changes in HDAC6 activity ultimately affected the activity of the AR but here we show that HDAC6 is also decreased in PC3 cells which are AR negative indicating that the effect of SFN on AR may not be the only target for HDAC6. Importantly, over-expression of HDAC6 rescues PC3 cells from SFN-induced decreases in cell viability suggesting that HDAC6 plays a critical role in mediating its cytotoxicity. Thus, the inhibition of HDAC6 could play a key role in the stabilization of microtubule networks, disruption of tubulin polymerization and ultimately contribute to the mitotic cell cycle arrest observed with SFN treatment $[35,36]$. The link between tubulin acetylation and selectively toxicity towards cancer cells has been reported after treatment with the HDAC6 specific inhibitor tubacin. Treatment with tubacin induced a dose and time dependent increase in $\alpha$-tubulin acetylation and ultimately cytoxicity in several multiple myeloma cell lines and bone marrow plasma cells but had no effect in normal peripheral blood mononuclear cells [37]. Autophagy is another cellular response that is partially mediated by HDAC6 because it functions to deliver polyubiquitinated proteins to aggresomes for degradation by binding both the polyubiquitinated proteins and the microtubule motor dynein [28]. SFN treatment in PC3 and $\mathrm{LNCaP}$ prostate cells results in an induction of autophagy and partial inhibition of cytochrome $\mathrm{C}$ release and apoptosis [38]. The decrease in HDAC6 protein we observed in BPH1, LnCap and PC3 cells may divert the cell fate away from survival (autophagy) towards cell death (apoptosis) by decreasing the formation of autophagic aggresomes. Further investigation into the potential roles of $\alpha$-tubulin acetylation and the reduction in HDAC6 levels in the selectivity of SFN will provide insights into the mechanisms for SFN mediated cancer cell death.

The use of HDAC inhibitors in cancer prevention and treatment has become an intense area of research. These data provide further support for the relevance of SFN as a dietary HDAC inhibitor and chemopreventive agent by showing that SFN can selectively target BPH1, LnCap and PC3 prostate cells while leaving normal PrEC prostate cells virtually unaffected. This selectivity opens the door to a wide range of new scientific questions that will help in understanding the many mechanisms of action for SFN. The data presented here, taken with the previous reports of SFN action, show that SFN can target multiple steps in the carcinogenesis pathway and make it a promising cancer prevention agent.

\section{Abbreviations}
AFU
arbitrary fluorescence units
GST
Glutathione-S-transferase 


$\begin{array}{ll}\text { HAT } & \text { histone acetyltransferase } \\ \text { HDAC } & \text { histone deacetylase } \\ \text { HO1 } & \text { heme oxygenase } \\ \text { NQO1 } & \text { NAD(P)H:quinone reductase } \\ \text { ROS } & \text { reactive oxygen species } \\ \text { SAHA } & \text { suberoylanilide hydroxamic acid } \\ \text { SFN } & \text { sulforaphane } \\ \text { SFN-GSH } & \text { sulforaphane-glutathione } \\ \text { SFN-Cys } & \text { sulforaphane-cysteine } \\ \text { SFN-NAC } & \text { sulforaphane-N-acetylcysteine } \\ \text { TSA } & \text { trichostatin A }\end{array}$

\section{Acknowledgments}

This work was supported by NIH grants CA090890, CA122906, Oregon AES (OR00735), instrument grant 1S10RR022589, and the Environmental Health Science Center at Oregon State University (NIEHS P30 ES00210). We acknowledge support from Dr. Jan Fred Stevens, Dr. Heather Kuipers and Jeffrey Morré with LC-MS/MS analyses, and technical assistance from Dr. Carmen Wong, Karin Hardin, and Dr. Yang Song.

\section{References}

1. Kristal AR, Lampe JW. Brassica vegetables and prostate cancer risk: a review of the epidemiological evidence. Nutr Cancer. 2002; 42:1-9. [PubMed: 12235639]

2. Higdon JV, Delage B, Williams DE, Dashwood RH. Cruciferous vegetables and human cancer risk: epidemiologic evidence and mechanistic basis. Pharmacol Res. 2007; 55:224-236. [PubMed: 17317210]

3. Fahey JW, Zhang Y, Talalay P. Broccoli sprouts: an exceptionally rich source of inducers of enzymes that protect against chemical carcinogens. Proc Natl Acad Sci USA. 1997; 94:1036710372. [PubMed: 9294217]

4. Singh SV, Herman-Antosiewicz A, Singh AV, Lew KL, et al. Sulforaphane-induced G2/M Phase Cell Cycle Arrest Involves Checkpoint Kinase 2-mediated Phosphorylation of Cell Division Cycle 25C. J. Biol. Chem. 2004; 279:25813-25822. [PubMed: 15073169]

5. Wang L, Liu D, Ahmed T, Chung FL, et al. Targeting cell cycle machinery as a molecular mechanism of sulforaphane in prostate cancer prevention. Int J Oncol. 2004; 24:187-192. [PubMed: 14654956]

6. Myzak MC, Karplus PA, Chung FL, Dashwood RH. A novel mechanism of chemoprotection by sulforaphane: inhibition of histone deacetylase. Cancer Res. 2004; 64:5767-5774. [PubMed: 15313918]

7. Myzak MC, Hardin K, Wang R, Dashwood RH, Ho E. Sulforaphane inhibits histone deacetylase activity in BPH-1, LnCaP and PC-3 prostate epithelial cells. Carcinogenesis. 2006; 27:811-819. [PubMed: 16280330]

8. Myzak MC, Tong P, Dashwood WM, Dashwood RH, Ho E. Sulforaphane retards the growth of human PC-3 xenografts and inhibits HDAC activity in human subjects. Exp Biol Med (Maywood). 2007; 232:227-234. [PubMed: 17259330]

9. Haberland M, Montgomery RL, Olson EN. The many roles of histone deacetylases in development and physiology: implications for disease and therapy. Nat Rev Genet. 2009; 10:32-42. [PubMed: 19065135]

10. Yang XJ, Seto E. HATs and HDACs: from structure, function and regulation to novel strategies for therapy and prevention. Oncogene. 2007; 26:5310-5318. [PubMed: 17694074] 
11. Hubbert C, Guardiola A, Shao R, Kawaguchi Y, et al. HDAC6 is a microtubule-associated deacetylase. Nature. 2002; 417:455-458. [PubMed: 12024216]

12. Matsuyama A, Shimazu T, Sumida Y, Saito A, et al. In vivo destabilization of dynamic microtubules by HDAC6-mediated deacetylation. Embo J. 2002; 21:6820-6831. [PubMed: 12486003]

13. Boyault C, Sadoul K, Pabion M, Khochbin S. HDAC6, at the crossroads between cytoskeleton and cell signaling by acetylation and ubiquitination. Oncogene. 2007; 26:5468-5476. [PubMed: 17694087]

14. Korkmaz CG, Fronsdal K, Zhang Y, Lorenzo PI, Saatcioglu F. Potentiation of androgen receptor transcriptional activity by inhibition of histone deacetylation--rescue of transcriptionally compromised mutants. J Endocrinol. 2004; 182:377-389. [PubMed: 15350180]

15. Butler LM, Agus DB, Scher HI, Higgins B, et al. Suberoylanilide hydroxamic acid, an inhibitor of histone deacetylase, suppresses the growth of prostate cancer cells in vitro and in vivo. Cancer Res. 2000; 60:5165-5170. [PubMed: 11016644]

16. Xu WS, Parmigiani RB, Marks PA. Histone deacetylase inhibitors: molecular mechanisms of action. Oncogene. 2007; 26:5541-5552. [PubMed: 17694093]

17. Dokmanovic M, Perez G, Xu W, Ngo L, et al. Histone deacetylase inhibitors selectively suppress expression of HDAC7. Mol Cancer Ther. 2007; 6:2525-2534. [PubMed: 17876049]

18. Ungerstedt JS, Sowa Y, Xu WS, Shao Y, et al. Role of thioredoxin in the response of normal and transformed cells to histone deacetylase inhibitors. Proc Natl Acad Sci USA. 2005; 102:673-678. [PubMed: 15637150]

19. Atadja P, Gao L, Kwon P, Trogani N, et al. Selective growth inhibition of tumor cells by a novel histone deacetylase inhibitor, NVP-LAQ824. Cancer Res. 2004; 64:689-695. [PubMed: 14744786]

20. Piekarz R, Bates S. A review of depsipeptide and other histone deacetylase inhibitors in clinical trials. Curr Pharm Des. 2004; 10:2289-2298. [PubMed: 15279609]

21. Kelly WK, Richon VM, O'Connor O, Curley T, et al. Phase I clinical trial of histone deacetylase inhibitor: suberoylanilide hydroxamic acid administered intravenously. Clin Cancer Res. 2003; 9:3578-3588. [PubMed: 14506144]

22. Al Janobi AA, Mithen RF, Gasper AV, Shaw PN, et al. Quantitative measurement of sulforaphane, iberin and their mercapturic acid pathway metabolites in human plasma and urine using liquid chromatography-tandem electrospray ionisation mass spectrometry. J Chromatogr B Analyt Technol Biomed Life Sci. 2006; 844:223-234.

23. Frank SR, Schroeder M, Fernandez P, Taubert S, Amati B. Binding of c-Myc to chromatin mediates mitogen-induced acetylation of histone $\mathrm{H} 4$ and gene activation. Genes Dev. 2001; 15:2069-2082. [PubMed: 11511539]

24. Herman-Antosiewicz A, Xiao H, Lew KL, Singh SV. Induction of p21 protein protects against sulforaphane-induced mitotic arrest in LNCaP human prostate cancer cell line. Mol Cancer Ther. 2007; 6:1673-1681. [PubMed: 17513615]

25. Richon VM, Sandhoff TW, Rifkind RA, Marks PA. Histone deacetylase inhibitor selectively induces p21WAF1 expression and gene-associated histone acetylation. Proc Natl Acad Sci USA. 2000; 97:10014-10019. [PubMed: 10954755]

26. Ocker M, Schneider-Stock R. Histone deacetylase inhibitors: Signalling towards p21cip1/waf1. The International Journal of Biochemistry \& Cell Biology. 2007; 39:1367-1374.

27. Bruserud O, Stapnes C, Ersvaer E, Gjertsen BT, Ryningen A. Histone deacetylase inhibitors in cancer treatment: a review of the clinical toxicity and the modulation of gene expression in cancer cell. Curr Pharm Biotechnol. 2007; 8:388-400. [PubMed: 18289048]

28. Rodriguez-Gonzalez A, Lin T, Ikeda AK, Simms-Waldrip T, et al. Role of the aggresome pathway in cancer: targeting histone deacetylase 6-dependent protein degradation. Cancer Res. 2008; 68:2557-2560. [PubMed: 18413721]

29. Simms-Waldrip T, Rodriguez-Gonzalez A, Lin T, Ikeda AK, et al. The aggresome pathway as a target for therapy in hematologic malignancies. Mol. Genet. Metab. 2008; 94:283-286. [PubMed: 18472289] 
30. Gibbs A, Schwartzman J, Deng V, Alumkal J. Sulforaphane destabilizes the androgen receptor in prostate cancer cells by inactivating histone deacetylase 6. Proc Natl Acad Sci USA. 2009:1666316668. [PubMed: 19805354]

31. Nakagawa M, Oda Y, Eguchi T, Aishima S, et al. Expression profile of class I histone deacetylases in human cancer tissues. Oncol Rep. 2007; 18:769-774. [PubMed: 17786334]

32. Weichert W, Roske A, Gekeler V, Beckers T, et al. Histone deacetylases 1, 2 and 3 are highly expressed in prostate cancer and HDAC2 expression is associated with shorter PSA relapse time after radical prostatectomy. Br J Cancer. 2008; 98:604-610. [PubMed: 18212746]

33. Li Y, Li X, Guo B. Chemopreventive agent 3,3'-diindolylmethane selectively induces proteasomal degradation of class I histone deacetylases. Cancer Res. 70:646-654. [PubMed: 20068155]

34. Spurling CC, Godman CA, Noonan EJ, Rasmussen TP, et al. HDAC3 overexpression and colon cancer cell proliferation and differentiation. Mol Carcinog. 2008; 47:137-147. [PubMed: 17849419]

35. Azarenko O, Okouneva T, Singletary KW, Jordan MA, Wilson L. Suppression of microtubule dynamic instability and turnover in MCF7 breast cancer cells by sulforaphane. Carcinogenesis. 2008; 29:2360-2368. [PubMed: 18952594]

36. Jackson SJ, Singletary KW. Sulforaphane: a naturally occurring mammary carcinoma mitotic inhibitor, which disrupts tubulin polymerization. Carcinogenesis. 2004; 25:219-227. [PubMed: 14578157]

37. Hideshima T, Bradner JE, Wong J, Chauhan D, et al. Small-molecule inhibition of proteasome and aggresome function induces synergistic antitumor activity in multiple myeloma. Proc Natl Acad Sci USA. 2005; 102:8567-8572. [PubMed: 15937109]

38. Herman-Antosiewicz A, Johnson DE, Singh SV. Sulforaphane Causes Autophagy to Inhibit Release of Cytochrome c and Apoptosis in Human Prostate Cancer Cells. Cancer Res. 2006; 66:5828-5835. [PubMed: 16740722] 
A
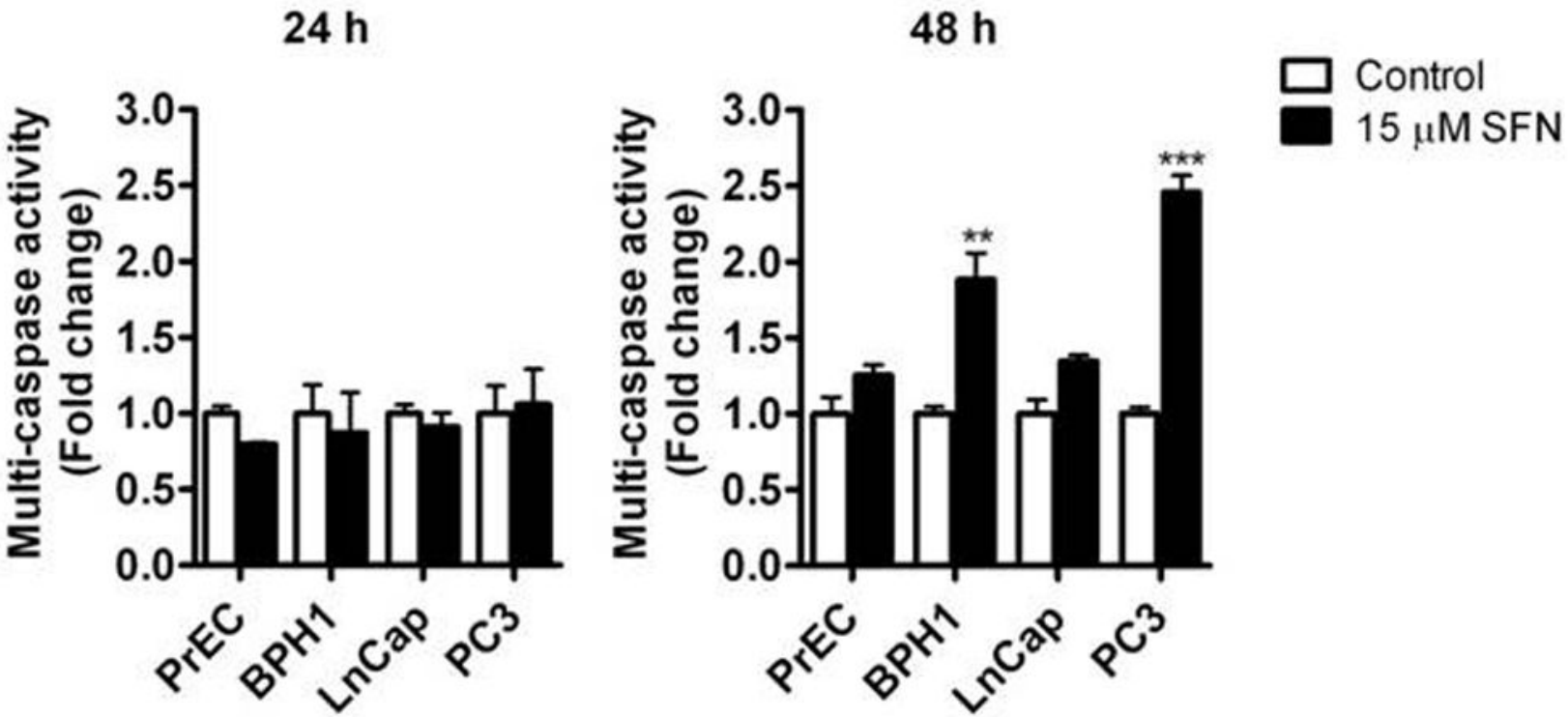

B
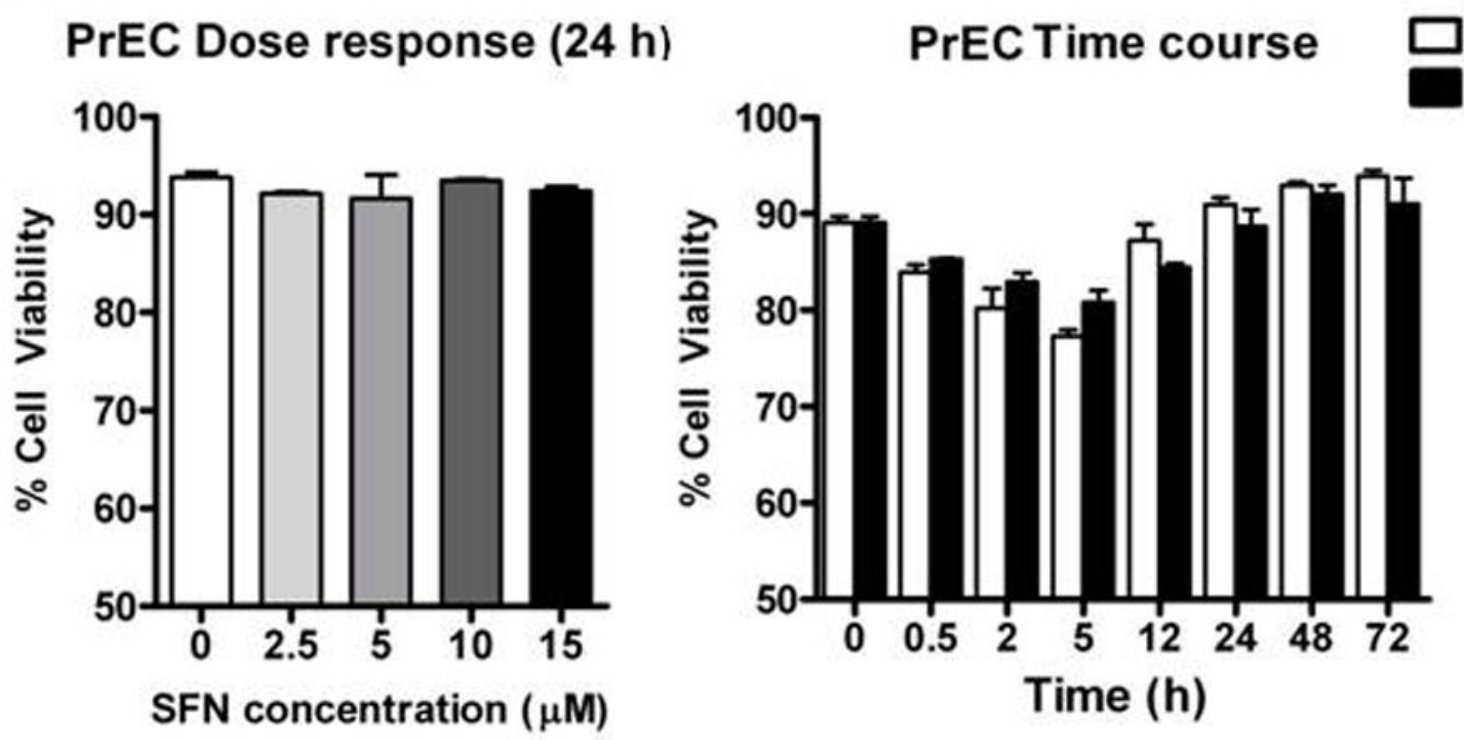

Figure 1.

SFN preferentially induces apoptosis in BPH1 and PC3 cells. Cells were treated with DMSO (control) (white bars) or $15 \mu \mathrm{M}$ SFN (black bars) for 24 and $48 \mathrm{~h}$ and harvested for apoptosis analysis. (A) Multi-caspase activity analyzed by one-way ANOVA. (B) Trypan blue exclusion assay in PrEC at increasing doses of SFN (left) and $15 \mu \mathrm{M}$ SFN $72 \mathrm{~h}$ time course (right), analyzed by one-way ANOVA and two-way ANOVA, respectively. Data in graphs represent mean $\pm \operatorname{SEM}(\mathrm{n}=3)$. Statistical significance: $* * \mathrm{p}<0.01, * * * \mathrm{p}<0.001$ using Dunnett's post-test. 
A
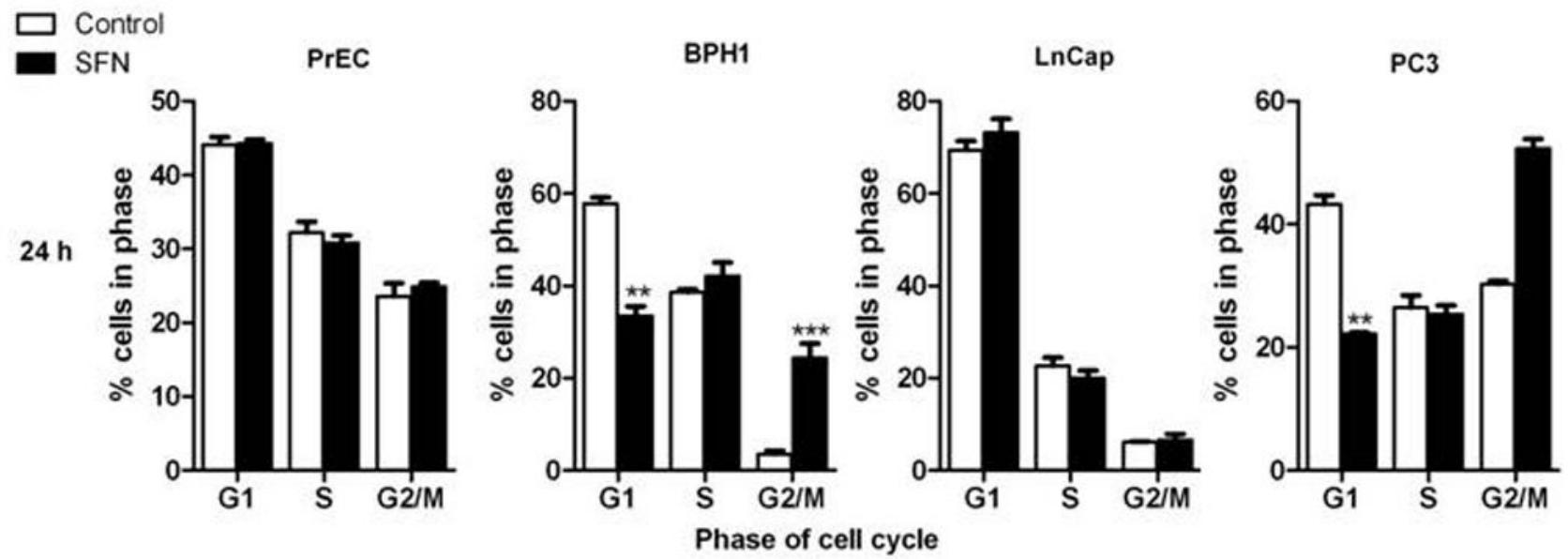

B
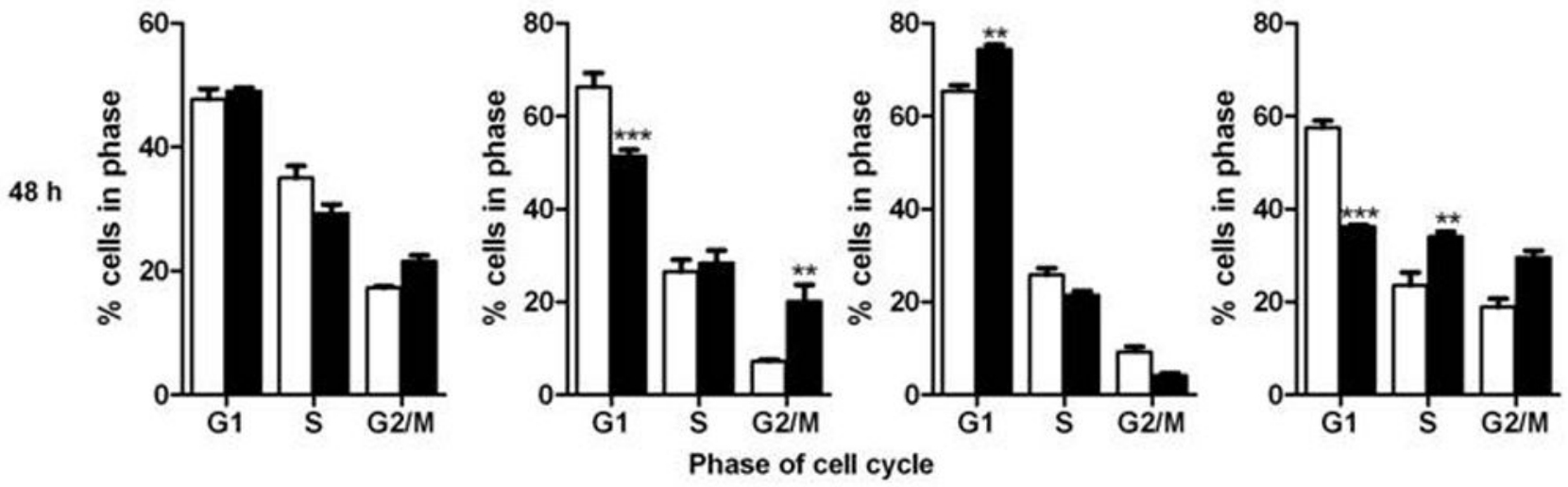

Figure 2.

SFN preferentially induces cell cycle arrest in BPH1, LnCap and PC3 cells. Cells were treated with DMSO (control) (white bars) or $15 \mu \mathrm{M} \mathrm{SFN} \mathrm{(black} \mathrm{bars)} \mathrm{for} 24$ and $48 \mathrm{~h}$ and harvested for cell cycle analysis. Distribution of cells (in percentage) in the $G_{1}, S$, and $G_{2} / M$ phases of the cell cycle. Data in bar graphs represent mean \pm SEM $(n=3)$. Statistical significance: $* * \mathrm{p}<0.01, * * * \mathrm{p}<0.001$ using Dunnett's post-test. 


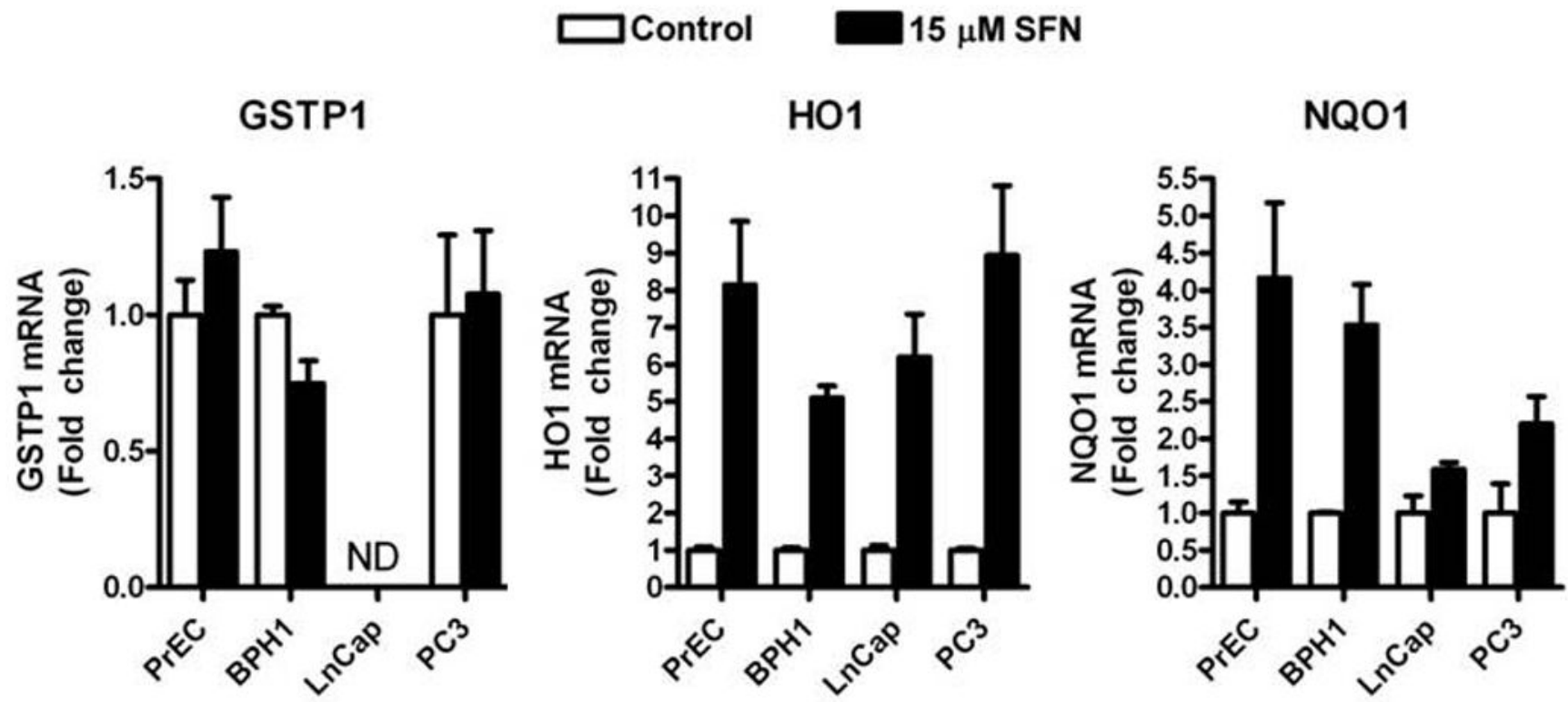

Figure 3.

SFN increases the level of HO1 and NQO1 mRNA in PrEC, BPH1, LnCap and PC3 cells. Cells were treated with DMSO (control) (white bars) or $15 \mu \mathrm{M}$ SFN (black bars) for $12 \mathrm{~h}$ and harvested for qRT-PCR. GSTP1 (left), HO1 (middle) and NQO1 (right). Data in bar graphs represent mean \pm SEM $(n=3)$. ND=none detected. Data were analyzed by 1 -way ANOVA and Dunnett's post-test. 

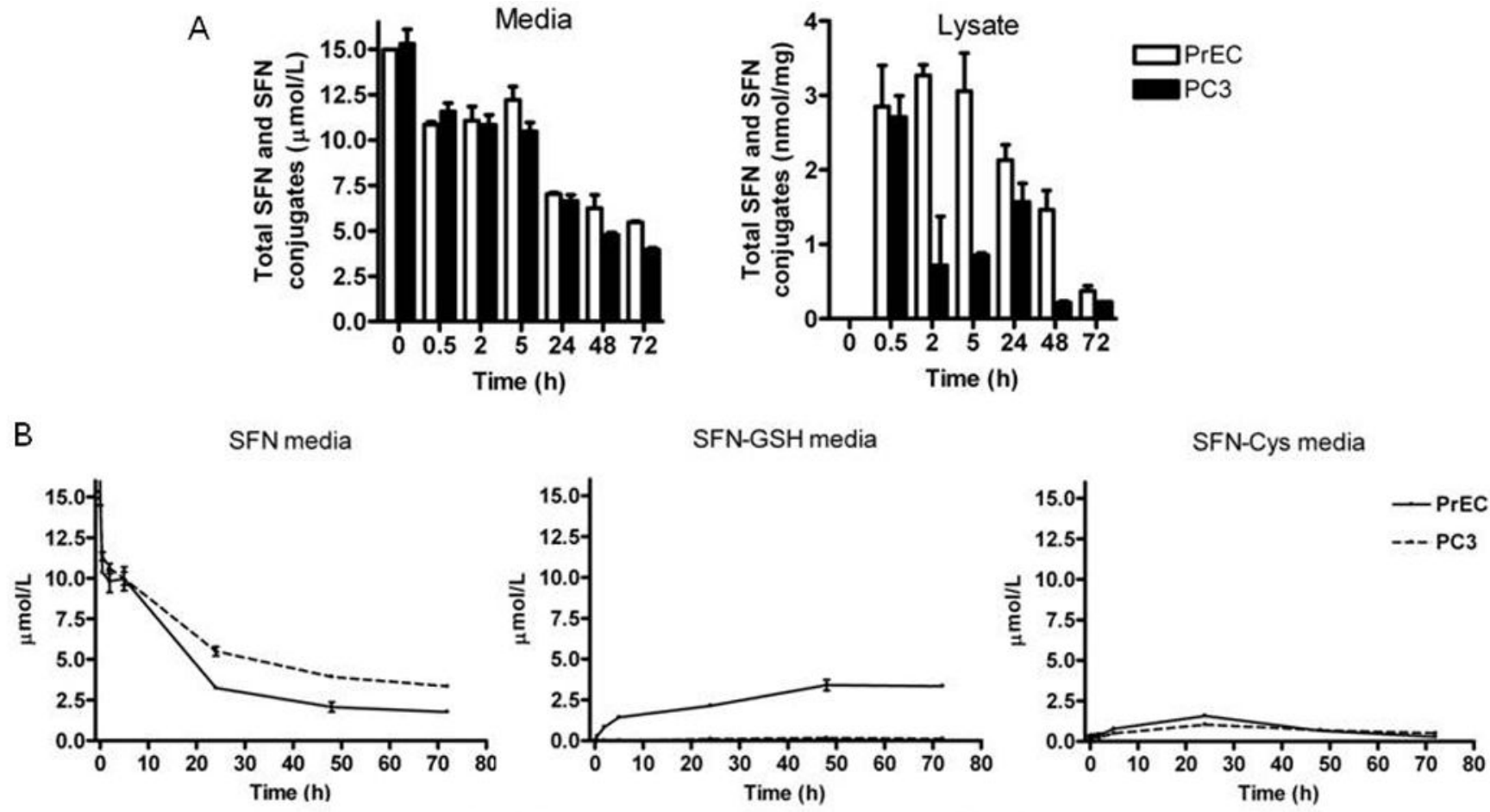

C

SFN-GSH lysate

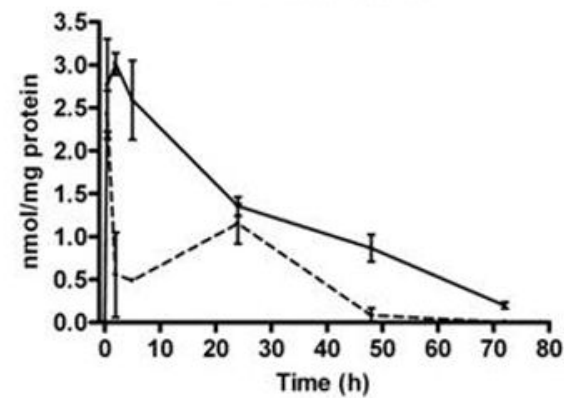

SFN-Cys lysate

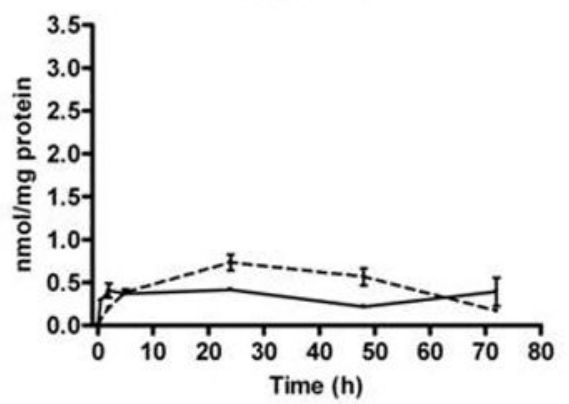

Figure 4.

SFN is metabolized similarly in PrEC and PC3 cells. Cells were treated and harvested as described in the methods. (A) The sum of all SFN compounds in culture media (left) and lysate (right) from PrEC (white bars) and PC3 (black bars). (B) Concentrations of free SFN (left), SFN-GSH (middle) and SFN-Cys (right) in the cell culture media from PrEC (dashed lines) and PC3 (solid lines). (C) Concentrations of SFN-GSH (left) and SFN-Cys (right) in the cell lysates. Data in bar graphs represent mean $\pm \operatorname{SEM}(n=2)$. 


\section{$\square$ Control}

$24 \mathrm{~h}$

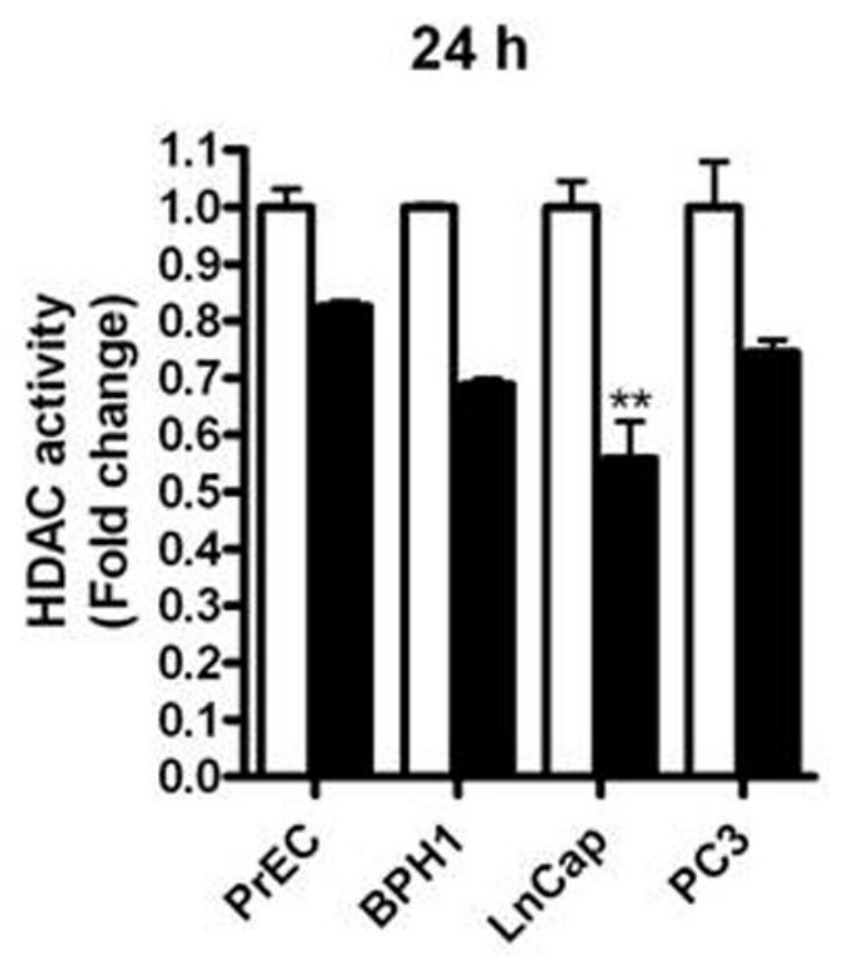

\section{$15 \mu \mathrm{M}$ SFN}

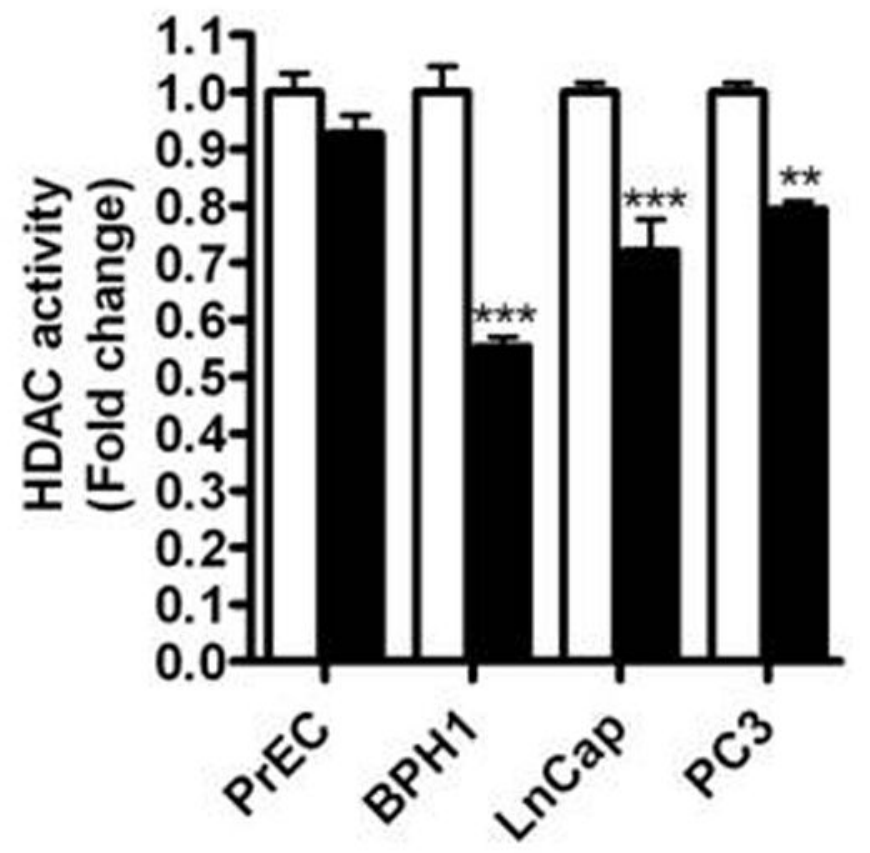

Figure 5.

SFN selectively reduces HDAC activity in BPH1, LnCap and PC3 but not normal PrEC prostate cells. Cells were treated with DMSO (control) (white bars) or $15 \mu \mathrm{M}$ SFN (black bars) for 24 and $48 \mathrm{~h}$ and harvested for HDAC activity. Data in bar graphs represent mean \pm SEM ( $n=3)$. Statistical significance: $* * p<0.01, * * * p<0.001$ using Dunnett's post-test. 
A

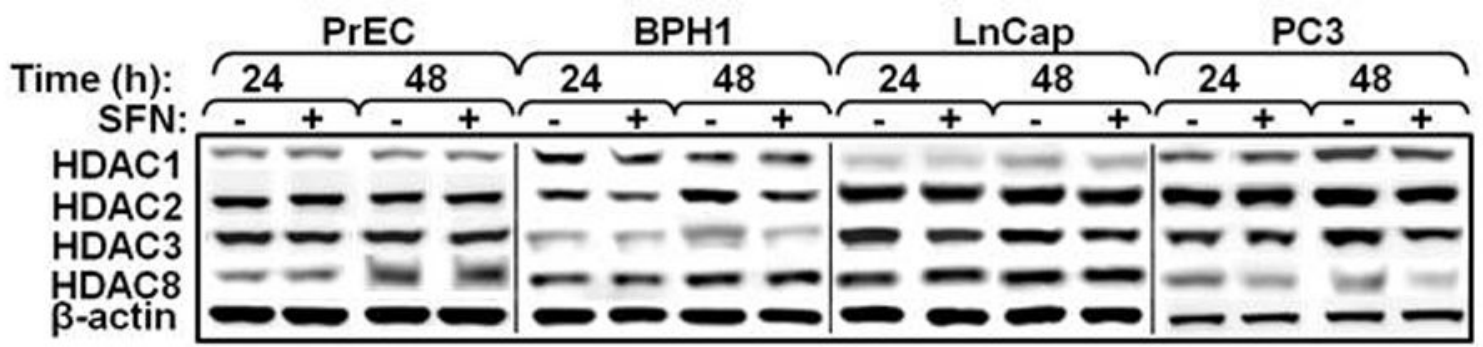
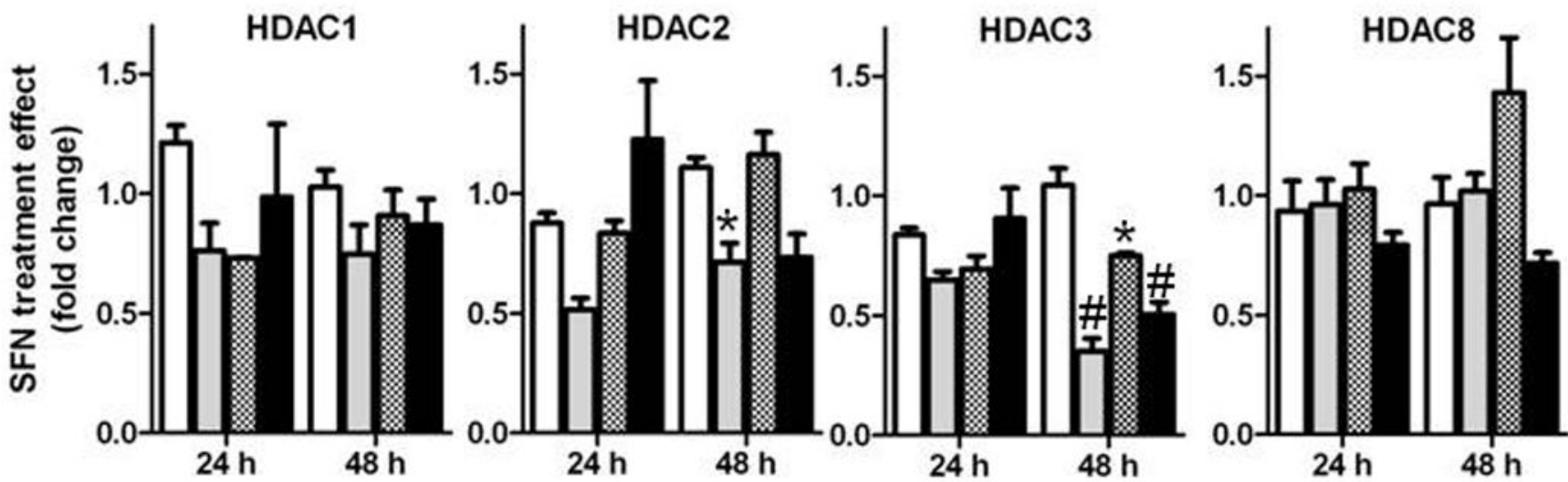

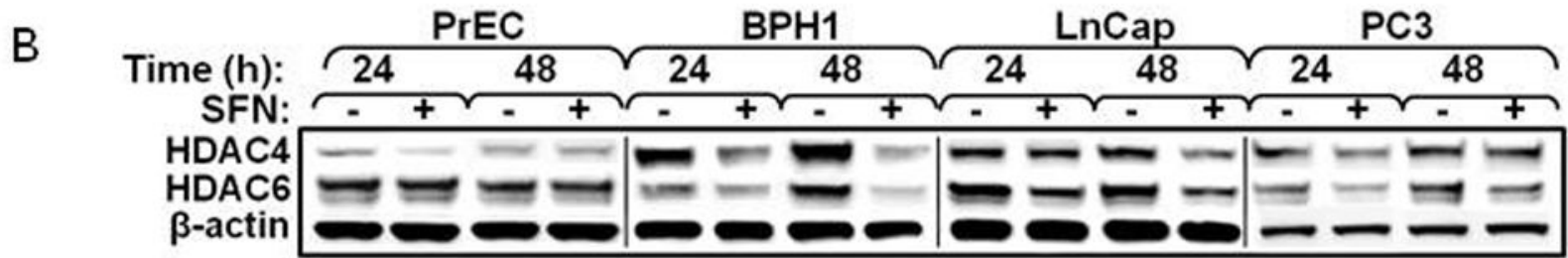
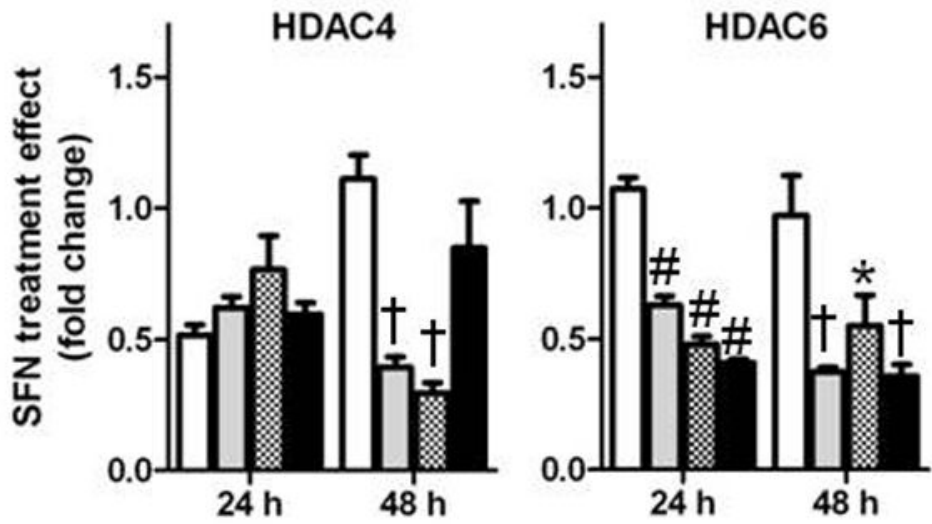

$\square$ PrEC

$\square \mathrm{BPH} 1$

\&nCap

- PC3

Figure 6.

SFN selectively reduces several class I and class II HDAC proteins in BPH1, LnCap and PC3 but not normal PrEC prostate cells. Western blot and densitometry of class I (A) and class II (B) HDACs at 24 and $48 \mathrm{~h}$. Data in bar graphs represent mean \pm SEM $(n=3)$.

Statistical significance: $* \mathrm{p}<0.01, \# \mathrm{p}<0.01 \uparrow \mathrm{p}<0.001$ using Dunnett's post-test comparing PrEC to the other cell lines within each time point. 
$A$
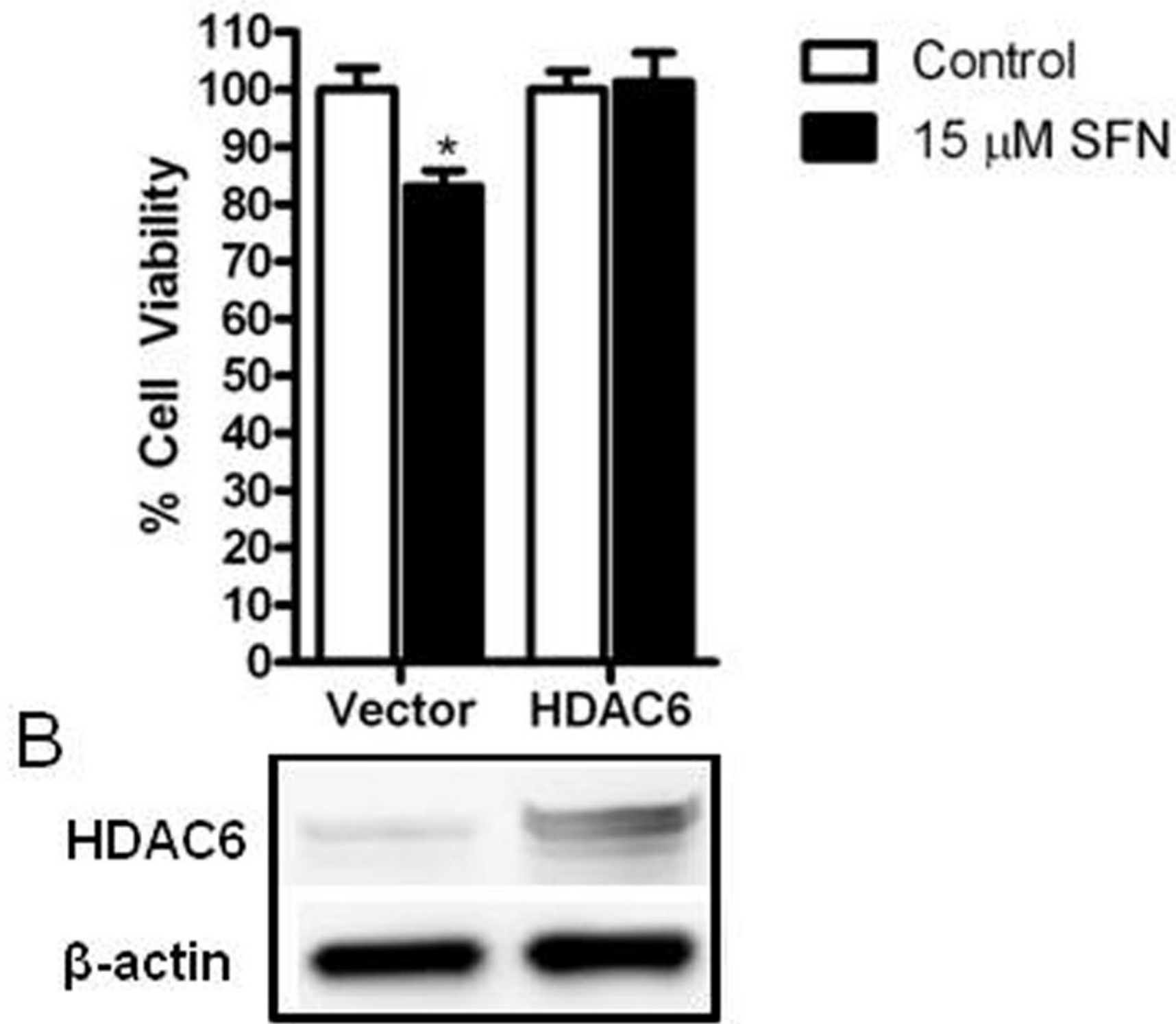

Figure 7.

HDAC6 over-expression blocks SFN induced growth inhibition in PC3 cells. A) Cells were transfected with empty vector or HDAC6 and treated with DMSO (control) (white bars) or $15 \mu \mathrm{M}$ SFN (black bars) for $48 \mathrm{hr}$ and assayed for cell proliferation. Data in bar graphs represent mean \pm SEM $(n=3)$. Statistical significance: * $p<0.05$ comparing SFN effect in vector versus SFN effect in HDAC6 treated groups using Student's t-test. B) Western blots depicting relative expression levels of HDAC6 in empty vector and HDAC6 transfected cells. 

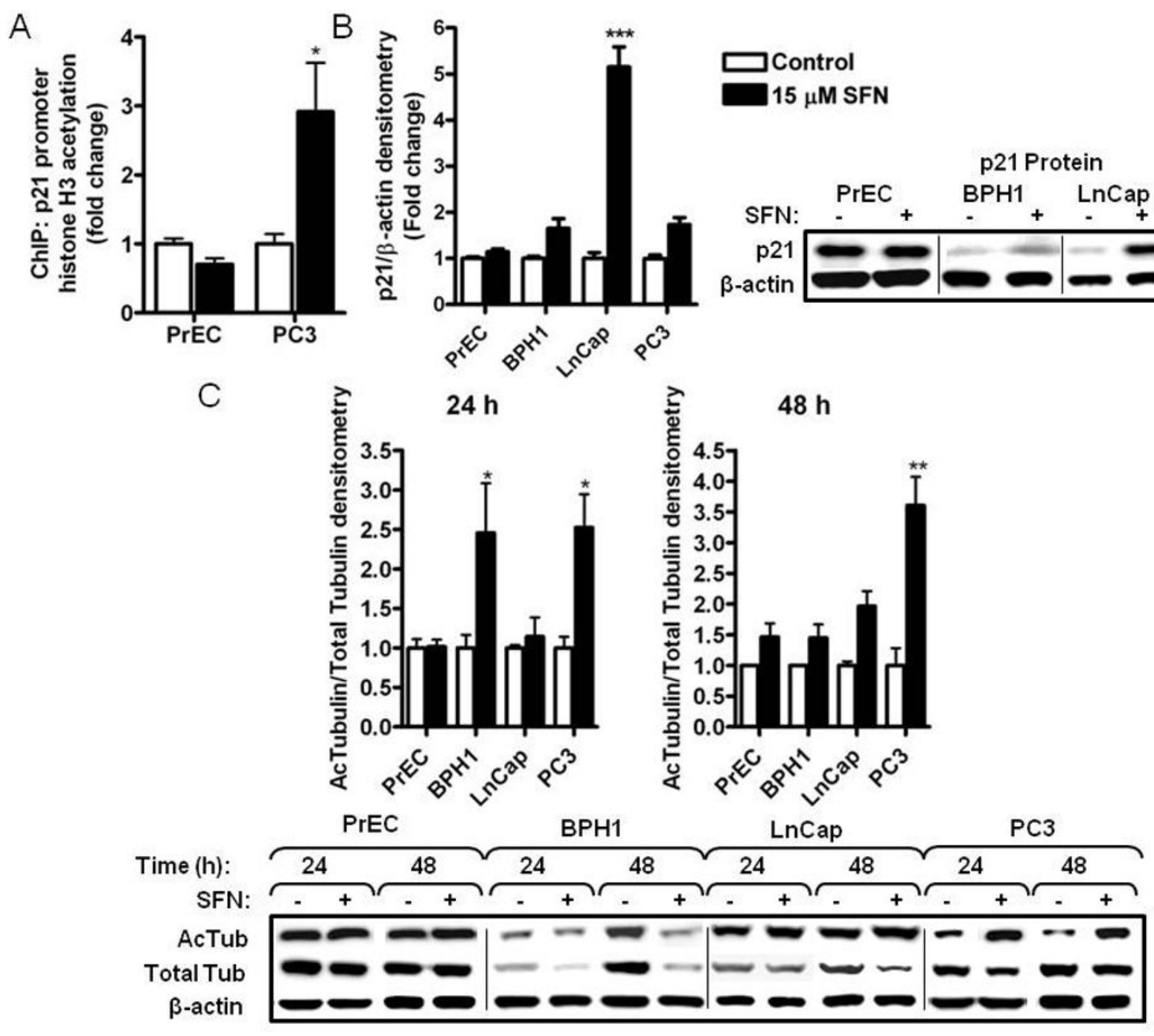

$24 \mathrm{~h}$

Figure 8.

SFN treatment selectively induces histone $\mathrm{H} 3$ acetylation at the $P 21$ promoter, $\mathrm{p} 21$ protein and tubulin acetylation in BPH1, LnCap and PC3 but not normal PrEC prostate cells. Cells were treated with DMSO (control) (white bars) or $15 \mu \mathrm{M} \mathrm{SFN} \mathrm{(black} \mathrm{bars)} \mathrm{for} \mathrm{the} \mathrm{time}$ indicated and harvested for ChIP or western blots. (A) ChIP for acetylated histone $\mathrm{H} 3$ at the $P 21$ promoter at $48 \mathrm{~h}$. For normalization between samples the immunoprecipitated DNA

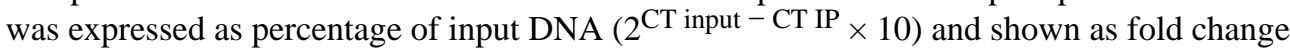
compared to control treatments. TSA was included as a positive control for histone acetylation (data not shown). Data were analyzed by Student's t-test; *p<0.05. (B) Densitometry and western blots for p21 protein at $24 \mathrm{~h}$. (C) Western blot and densitometry of acetylated tubulin and total tubulin at 24 and $48 \mathrm{~h}$. Data in bar graphs represent mean \pm $\operatorname{SEM}(\mathrm{n}=3)$. Data for B and C were analyzed by one-way ANOVA; ${ }^{*} \mathrm{p}<0.05, * * \mathrm{p}<0.01$, $* * * \mathrm{p}<0.001$ using Dunnett's post-test. 